\title{
Feasibility of a computerized intervention for offenders with substance use disorders: a research note
}

\author{
Michael Chaple • Stanley Sacks • \\ Karen McKendrick • Lisa A. Marsch • \\ Steven Belenko • Carl Leukefeld • \\ Michael Prendergast • Michael French
}

Published online: 18 October 2013

(C) The Author(s) 2013. This article is published with open access at Springerlink.com

\begin{abstract}
Objectives Despite evidence that treatment is effective in reducing recidivism among inmates with substance use problems, scarce resources mean that few of those in need of treatment actually receive it. Computerized substance abuse interventions could be used to expand access to treatment in prisons without placing an undue burden on resources. The major aim of the study was to compare treatment conditions in terms of their service utilization, skills acquisition, and treatment satisfaction.

Methods The study recruited men and women with substance use disorders from 10 prisons in 4 states. In an open label clinical trial, 494 subjects were randomly assigned either to the Experimental condition, a computerized drug treatment
\end{abstract}

M. Chaple $(\bowtie) \cdot$ S. Sacks $\cdot$ K. McKendrick

Center for the Integration of Research \& Practice (CIRP), National Development \& Research Institutes, Inc. (NDRI), 71 W 23 Street, 8th Floor, New York, NY 10010, USA

e-mail: chaple@ndri.org

S. Sacks

e-mail: stansacks@mac.com

K. McKendrick

e-mail: kmckendrick@mac.com

L. A. Marsch

Psychiatry, Dartmouth Medical School, 1 Rope Ferry Road, Hanover, NH 03755-1404, USA

e-mail: Lisa.A.Marsch@Dartmouth.edu

S. Belenko

Department of Criminal Justice, Temple University, Gladfelter Hall, 5th Fl, 1115 Polett Walk, Philadelphia, PA 19122, USA

e-mail: sbelenko@temple.edu

C. Leukefeld

Department of Behavioral Science, University of Kentucky, 111 Medical Behavioral Science Bldg 0086, Lexington, KY 40536-0086, USA

e-mail: cleukef@uky.edu 
intervention, the Therapeutic Education System (TES; $n=249$ ), or to the Control condition, Standard Care $(n=245)$. Chi-square tests compared groups on categorical variables and independent samples $t$ tests were used for interval level continuous variables.

Results Initial evidence demonstrated: (1) comparable group rates of session attendance and high rates of TES module completion for experimental subjects; (2) comparable group gains in the development of coping skills; and (3) a more favorable view of TES than of Standard Care.

Conclusions Collectively, these results show that a computerized intervention, such as TES, can be implemented successfully in prison. Given the barriers to the delivery of substance abuse treatment typically encountered in correctional settings, computerized interventions have the potential to fill a significant treatment gap and are particularly well suited to inmates with mild to moderate substance use disorders who often are not treated.

Keywords Computerized intervention - Correctional settings · Offenders · Substance abuse treatment . Substance use

\section{Introduction}

Substance use and incarceration

The criminal justice system supervises some 7.2 million adults; of these, 2.2 million are incarcerated (Glaze and Parks 2012). Offenders exhibit disproportionately high rates of substance use and HIV risk behavior, such as injection drug use and risky sexual behaviors (Calsyn et al. 2006; Maruschak and Beaver 2009; Prendergast et al. 2001). An estimated 50-66 \% of offenders meet DSMIV criteria (American Psychiatric Association [APA] 2000) for substance dependence or abuse (Mumola and Karberg 2006), whereas the rate in the general U.S. population aged 12 or older is only $9 \%$ (Substance Abuse and Mental Health Administration [SAMHSA] 2011).

Correctional facilities are ideal settings in which to deliver substance abuse and HIV prevention interventions. Incarcerated persons are accessible, with few demands on their time, and are encouraged to re-evaluate their life choices. Once released from prison, untreated substance-abusing offenders are more likely to relapse to drug use and be reincarcerated than those who have received treatment (Knight et al. 1999; Matheson et al. 2011). Yet, despite the clear need for and success of substance abuse

\footnotetext{
M. Prendergast

Criminal Justice Research Group, Integrated Substance Abuse Programs (ISAP), University of California Los Angeles (UCLA), 11075 Santa Monica Blvd, Suite 100, Los Angeles 90025, USA e-mail: mprendergast@mednet.ucla.edu

M. French

Economics, Health Administration \& Policy Program, and Health Economics Research Group, University of Miami, 5202 University Dr, Merrick Bldg, Rm 121F, POB 248162, Coral Gables, FL 33124-2030, USA

e-mail: mfrench@miami.edu
} 
treatment, fewer than $25 \%$ of inmates with substance use conditions are treated while incarcerated (Belenko and Peugh 2005; Chandler et al. 2009; Mumola and Karberg 2006; National Institute on Drug Abuse [NIDA] 2011; Taxman et al. 2007). Access to evidence-based HIV prevention is also limited in prisons (Arriola et al. 2002; Hammett 2006).

Significant barriers impede the widespread adoption of evidence-based psychosocial interventions in correctional settings. Prison resources (monetary and human) for treatment services and for staff training are typically limited. The remote location of many prisons hinders staff recruitment, and counselors trained to provide communitybased treatment are not always well suited to working in prison environments (Center for Substance Abuse Treatment [CSAT] 2005; Farabee et al. 2011; Mears et al. 2003). Even if correctional staff were to implement an evidence-based intervention, staff turnover and high patient caseloads would threaten fidelity. Furthermore, because treatment needs within prison populations are variable, available treatment options are often inappropriate. The variability of treatment needs found within prison populations (Belenko and Peugh 2005), along with the institutional realities of accommodating treatment options within correctional settings, further limit the viability of evidence-based practices for substance use disorders, despite mounting evidence to suggest that treatment is effective in reducing crime and recidivism among offenders (Mitchell et al. 2007).

\section{Computerized treatments and the Therapeutic Education System (TES)}

Computerized interventions can expand access to psychosocial treatment in settings where treatment options are limited or not available. Computer programs have been developed for substance use (Marsch 2012; Marsch et al. 2007; Marsch and Dallery 2012; Riper et al. 2008), mental health (Postel et al. 2008), and HIV (Kiene and Barta 2006; Marsch and Bickel 2004). Computers have the capability to deliver complex interventions with fidelity at relatively low cost, and with minimal demands on staff time, which increases the potential for large-scale dissemination. Unfortunately, such computerized interventions have not been adequately tested in prisons or in other criminal justice settings.

The Therapeutic Education System (TES) is an interactive computerized psychosocial treatment program grounded in the Community Reinforcement Approach (CRA) and in Cognitive Behavioral Therapy (CBT). TES has been tested in several clinical trials and has a growing evidence base. A randomized clinical efficacy trial among opioid-dependent outpatients demonstrated that TES was as efficacious as CRA delivered by trained therapists, and was superior to standard treatment in promoting toxicology-verified drug abstinence among clients in outpatient substance abuse treatment (Bickel et al. 2008). Another clinical trial demonstrated that, as compared to standard treatment, the modules related to HIV prevention resulted in significantly greater knowledge of HIV prevention, increased self-reporting of risk behaviors, and a greater likelihood of intentions to practice safe sex. Furthermore, participants perceived the HIV prevention modules to be more useful (Marsch and Bickel 2004). TES has the potential to overcome resource challenges encountered in delivering treatment in prison and to make effective treatment more readily available to offenders in need of substance abuse treatment. The goals of this paper are to 
establish the feasibility of implementing TES in a prison setting by demonstrating inmate participation in treatment sessions, satisfaction with the computerized intervention, and skills acquisition.

\section{Materials and methods}

Trial design

The study recruited incarcerated men and women with substance use disorders from 10 prisons in 4 states ( 7 prisons in Colorado and one prison in each of Kentucky [KY], Pennsylvania [PA], and Washington [WA]). This was an open label trial; both participants and researchers knew the study conditions (i.e., treatment assignments). The investigators randomly assigned subjects to either the Experimental (E) condition, Therapeutic Education System (E-TES; $n=258$ ), or to the Control (C) Standard Care condition $(\mathrm{C} ; n=255)$. Randomization was stratified to ensure equal representation of $\mathrm{E}$ versus $\mathrm{C}$ in each prison.

\section{Study participants}

A total of 660 eligible male and female inmates were recruited to participate in the study. Eligibility required: (1) diagnosed as having a substance use disorder, but not currently receiving treatment services; (2) parole review or mandatory release within 4 to 6 months; (3) at least 18 years old; (4) English literacy; and (5) provision of signed informed consent form. A research assistant conducted an informed consent interview with each eligible inmate who expressed interest in the study. In this interview, the purposes of the study were reviewed, and the subject's role in the study was clearly explained. At the conclusion of the interview, those inmates who wanted to take part in the study signed an itemized form to attest to his/her voluntary participation. No coercion was used, and participation (or refusal to participate at any time prior to or during the study) did not affect the inmate's release or treatment status.

The NDRI Institutional Review Board (IRB) reviewed the study and its protocols prior to commencing data collection and annually thereafter. The NDRI IRB requested approval from the Office of Human Research Protections (OHRP), which was received on November 2, 2009, to apply to all participating sites. The IRBs from each of the three participating sites (Temple University, University of Kentucky, and University of California, Los Angeles) conducted initial and annual reviews of the study as conducted at the respective site; in some cases (e.g., the University of Kentucky), although a blanket approval was in place, the participating site also requested and received OHRP approval for their site.

A 3-member Data and Safety Monitoring Board (DSMB) was established to provide oversight to the study. Research staff obtained information about each Serious Adverse Event (SAE) and compiled a preliminary report, which was sent to the Principal Investigator (PI) for review and his assessment of whether or not the SAE was related to study activities. The PI's final SAE report was then sent to the DSMB for their definitive determination of study-relatedness. Twenty-five reports were reviewed, none 
of which was found to be related to the study. The DSMB convened each year of the study to review the overall study, data collection, and preliminary results.

Although the study was open to all substance abusing offenders in need of treatment, both the $\mathrm{E}$ and $\mathrm{C}$ interventions targeted inmates with low and moderately severe substance use, and was not intended to be an alternative to higher levels of care, such as intensive outpatient or residential (e.g., Therapeutic Community) treatment. Approximately $13 \%(n=85)$ of all eligible inmates declined to participate in the study, citing such reasons as: not wanting more treatment, not wanting to participate in research, a conflict between study participation and the inmate's postrelease plans, or assigning higher priority to other activities during their remaining time in prison. Of the 575 eligible inmates, $89 \%(n=513)$ completed a baseline interview (administered immediately after the informed consent form was signed) and were randomly assigned to treatment. When prison authorities denied access to an inmate, or when parole eligibility changed, the baseline interview and randomization were not completed. Another 19 (9 E-TES; 10 C) subjects were removed from the study post-randomization because they were not released from prison during the follow-up period as had been expected. The final sample consisted of 494 offenders with substance use disorders who had been randomly assigned to E-TES or CStandard Care.

\section{Treatment conditions}

\section{Therapeutic Education System (E-TES)}

TES comprised 48 interactive, multimedia modules delivered for $2 \mathrm{~h}$ each week over 12 weeks. TES sessions were held in a classroom located in the correctional facility; each week, participants attended either one 2-h session or two 1-h sessions, depending on the facility. A "Core" set of 32 modules was typically completed in the first 8 weeks. In the remaining 4 weeks, participants either completed the 16 "Optional" modules, re-visited Core modules, or chose modules from both categories.

The Core modules were classified as: (1) Substance Use/Abuse (e.g., drug refusal skills, coping with thoughts about using); (2) Risk Reduction for HIV, AIDS and Sexually Transmitted Infections (e.g., drug use, HIV and hepatitis, identifying/managing triggers for risky sex); (3) Cognitive and Emotional Regulation (e.g., Managing Negative Thinking, Anger Management); and (4) Psychosocial Functioning (e.g., Effective Problem Solving, Communication Skills). The Optional modules provided more advanced information on risk reduction and psychosocial functioning. Because modules focused on developing improved approaches to decision-making skills, all modules had particular relevance for substance-abusing offenders.

TES content is theoretically grounded in research-based psychosocial treatments (Community Reinforcement Approach [CRA] and Cognitive Behavioral Therapy $[\mathrm{CBT}])$. In delivering this content, TES employs state-of-the-art, proven informational technologies to enhance knowledge, skills acquisition, and behavioral change. Specifically, TES uses "fluency-based" Computer-Assisted Instruction (CAI), grounded in the "precision teaching" approach (e.g., Binder 1993; Doane et al. 2005), which continually assesses an individual's grasp of the 
material, and adjusts the pace and level of repetition of material to promote mastery of the skills and information being taught. TES also creates an experiential learning environment, using interactive videos of peer actors who model various behaviors (e.g., drug refusal skills) to help the program user absorb the modeled behavior. Furthermore, TES employs a variety of interactive exercises to enhance learning (e.g., graphics and animation) and to personalize content (e.g., personalized functional analysis). In this way, TES ensures the delivery of sciencebased psychosocial treatment in a manner that promotes mastery of key information and skills. An electronic reporting system generates summaries of participant activity.

\section{Standard Care (C)}

Offenders in the C (Standard Care) control condition received substance abuse treatment from a Certified Addictions Counselor in 2-h group sessions (held once each week in a 2-h session or twice each week in 1-h sessions) over 8-12 weeks. The Standard Care curriculum addressed inmate recognition of the connections between feelings, thoughts and behaviors, and aimed to improve coping mechanisms to handle relapse triggers. In addition, the Standard Care program was designed to increase awareness of the connections between substance use and health/HIV risk to individuals. In Kentucky, Pennsylvania, and Washington, the control treatment condition met the Department of Corrections requirements for addiction treatment. In Colorado, the control condition was offered to individuals who were diagnosed with substance use disorders, but who had not been mandated to receive treatment prior to release, which meant their participation in treatment was essentially voluntary.

\section{Measures}

The primary measures of interest for this article span three domains: (1) treatment utilization (attendance for both groups and TES module completion for the E-TES group only); (2) skills acquisition (i.e. development of coping strategies); and (3) participant satisfaction. Attendance measures included the number of sessions inmates attended for both treatment conditions (these data were available for Colorado only; session attendance data were not obtained for the control groups at sites in KY, PA, or WA) and the number of TES modules completed for E-TES clients (TES software tracked this information for all sites). Skills acquisition was measured using the Coping Strategy Scale (CSS), a 48-item questionnaire that assesses key processes involved in modifying drug use behavior ( $\alpha=0.95$; Litt et al. 2003)

Using a 4-point scale (from "Never" to "Frequently"), subjects rated the frequency of their use of each of the strategies (e.g., "I avoid people associated with my drug or alcohol use"; "I leave places where people are using drugs or alcohol"; or "I spent time with people who reward me for not using drugs or alcohol") during the past 3 months (baseline interviews asked about the 3 months prior to incarceration; follow-up interviews asked about the 3 months prior to the interview). Client perceptions of treatment were derived from a 10-point scale (higher scores being 
more favorable) on 5 questions that explored the extent to which the subject found treatment satisfying, interesting, useful, easy to understand, and to yield new information. The participant satisfaction measure was added to the follow-up battery midway through the 3-month follow-up period, and was included in the 6-month battery only to capture those who did not report these data at the time of the 3-month follow-up; in the end, treatment satisfaction data were obtained for 376 study participants.

Follow-up data were collected for $87 \%$ of the sample at 3 months (89 \% for ETES and $84 \%$ for C) and $80 \%$ at 6 months (81\% for E-TES and $79 \%$ for C). Few differences between the groups were found for the vast majority of measures; however, retrieval bias did emerge for three measures. Compared to subjects not retrieved $(n=64)$, those with follow-up data $(n=430)$ were more likely: to have a lifetime arrest for a violent offense (61 vs. $45 \%$ ); to have ever used cannabis (88 vs. $78 \%$ ); and to have used alcohol to intoxication in the 6 months prior to incarceration (59 vs. $41 \%$ ).

\section{Analytic plan}

The major aim of this article was to report comparisons of the E-TES and C-Standard Care conditions on service utilization, skills acquisition, and treatment satisfaction. A profile comparison of subjects in the two treatment conditions was conducted to achieve a better understanding of the population and to detect any between-group baseline differences (see Table 1). Chi-square tests compared groups on categorical variables, and independent sample $t$ tests were used for interval level continuous variables.

With regard to service utilization, $t$ tests were used to compare the two treatment groups on attendance (e.g., number of sessions) in Colorado only, while descriptive statistics (e.g., percentages and means) were used to describe the number and types of TES modules that E-TES participants completed. Regarding skills acquisition, Generalized Linear Modeling was used to compare groups on repeated measures of the Coping Strategy Scale (CSS). Results are presented for the unadjusted model and for a model that included covariates selected on the basis of group differences at baseline or on findings from prior outcome studies. For the unadjusted model, CSS was the dependent measure and condition (E-TES; C-Standard Care) was the independent measure or factor. To improve the efficiency of the estimates and tests (Zhang et al. 2008), seven baseline covariates were added to the model: age, ethnicity, high school diploma/GED, age at first substance use, number of arrests, opioid use (past 6 months), and mean scores on the Circumstances, Motivation and Readiness (CMR) scales (i.e., Treatment motivation). Variables that captured group differences at baseline were included as covariates in the model to ensure that the observed effects could not be attributed to differences in group characteristics. The remaining covariates were included in the model according to their historical precedence (i.e., prior evidence of a strong correlation with an outcome). The model assumed a normal distribution and a log-link function. The C-Standard Care condition was scored as the reference group. Regarding participant satisfaction, $t$ tests were used to compare mean scores across treatment conditions. 
Table 1 Demographic and other background characteristics

\begin{tabular}{|c|c|c|c|c|}
\hline Domain/Measure & $\begin{array}{l}\text { E-TES } \\
(n=249) \\
\% / M(S D)\end{array}$ & $\begin{array}{l}\mathrm{C} \\
(n=245) \\
\% / \mathrm{M}(\mathrm{SD})\end{array}$ & $\begin{array}{l}\text { Total } \\
(n=494) \\
\% / \mathrm{M}(\mathrm{SD})\end{array}$ & $\chi^{2}(t$ test $)$ \\
\hline \multicolumn{5}{|l|}{ Demographics } \\
\hline Age & $36.7(9.4)$ & $36.5(9.8)$ & $36.6(9.6)$ & 0.799 \\
\hline Gender - male & 69.5 & 69.8 & 69.6 & 0.939 \\
\hline Race/ethnicity & & & & $0.009 * *$ \\
\hline Black/African American & 21.8 & 21.2 & 21.5 & \\
\hline White & 44.9 & 53.3 & 49.1 & \\
\hline Hispanic & 13.2 & 12.5 & 12.8 & \\
\hline High school diploma/GED & 77.5 & 82.0 & 79.7 & 0.219 \\
\hline L6 employment & 67.9 & 70.2 & 69.0 & 0.575 \\
\hline Never married & 46.0 & 45.7 & 45.8 & 0.407 \\
\hline Children & 76.2 & 72.2 & 74.2 & 0.314 \\
\hline Motivation for treatment & $39.0(10.2)$ & $40.5(9.4)$ & $39.7(9.8)$ & 0.091 \\
\hline \multicolumn{5}{|l|}{ Mental health } \\
\hline LT mental health treatment & 37.6 & 34.0 & 35.8 & 0.415 \\
\hline LT any mental health symptom & 59.4 & 57.8 & 58.6 & 0.710 \\
\hline Depression & 45.0 & 40.6 & 42.8 & 0.323 \\
\hline Anxiety & 47.0 & 44.7 & 45.8 & 0.606 \\
\hline Hallucinations & 13.7 & 14.8 & 14.2 & 0.727 \\
\hline LT prescribed medication & 29.3 & 30.7 & 30.0 & 0.731 \\
\hline \multicolumn{5}{|l|}{ Criminality } \\
\hline Age first arrest & $17.4(6.9)$ & $17.2(6.1)$ & $17.3(6.5)$ & 0.772 \\
\hline LT number of arrests & $18.2(18.7)$ & $18.3(21.5)$ & $18.2(20.1)$ & 0.994 \\
\hline LT arrest -substance-related offense & 71.1 & 72.2 & 71.7 & 0.775 \\
\hline LT arrest -property offense & 76.3 & 74.7 & 75.5 & 0.677 \\
\hline LT arrest -violent offense & 59.8 & 58.0 & 58.9 & 0.671 \\
\hline \multicolumn{5}{|l|}{ Substance use } \\
\hline Age first alcohol/drug use & $14.1(5.6)$ & $13.8(4.7)$ & $14.0(5.2)$ & 0.509 \\
\hline LT crack/cocaine & 70.3 & 71.0 & 70.6 & 0.857 \\
\hline LT opiates & 35.7 & 44.1 & 39.9 & 0.058 \\
\hline LT meth/amphetamines & 54.2 & 59.6 & 56.9 & 0.228 \\
\hline L6 drug use & 77.0 & 81.6 & 79.3 & 0.214 \\
\hline L6 substance most problematic & & & & $0.009^{* *}$ \\
\hline Alcohol & 38.7 & 25.2 & 32.0 & \\
\hline Cannabis & 12.6 & 12.8 & 12.7 & \\
\hline Crack/cocaine & 18.5 & 17.1 & 17.8 & \\
\hline Opiates & 4.6 & 11.1 & 7.8 & \\
\hline Meth/amphetamines & 17.2 & 23.9 & 20.6 & \\
\hline Prior substance-abuse treatment & 59.5 & 60.3 & 59.9 & 0.854 \\
\hline
\end{tabular}


Table 1 (continued)

\begin{tabular}{|c|c|c|c|c|}
\hline Domain/Measure & $\begin{array}{l}\text { E-TES } \\
(n=249) \\
\% / M(S D)\end{array}$ & $\begin{array}{l}\mathrm{C} \\
(n=245) \\
\% / \mathrm{M}(\mathrm{SD})\end{array}$ & $\begin{array}{l}\text { Total } \\
(n=494) \\
\% / \mathrm{M}(\mathrm{SD})\end{array}$ & $\chi^{2}(t$ test $)$ \\
\hline \multicolumn{5}{|l|}{ HIV risk } \\
\hline LT injection drug use & 22.3 & 28.0 & 25.1 & 0.145 \\
\hline L6 injection drug use & 14.5 & 20.9 & 17.6 & 0.061 \\
\hline L6 num sex partners & $4.1(7.8)$ & $3.7(7.7)$ & $3.9(7.8)$ & 0.567 \\
\hline L3 unprotected sex risk ${ }^{a}$ & 63.2 & 68.7 & 65.9 & 0.194 \\
\hline
\end{tabular}

$L T$ Lifetime; $L 6$ last 6 months prior to involvement with the criminal justice system; $L 3$ last 3 months prior to involvement with the criminal justice system

${ }^{a}$ Includes unprotected sex while high/partner high, when exchanging sex for money/drugs, with an intravenous drug user, with someone HIV+, with partner who refused to use condom, when afraid to ask for condom use

${ }^{*} p<0.05,{ }^{* *} p<0.001$

\section{Results}

Profiles

\section{Overall}

Table 1 presents profile information for the baseline sample $(n=494)$. The majority was male (70\%), in their mid-30s (mean 36.6; standard deviation [SD] 9.6), with a high school diploma/GED (80 \%). More than two-thirds (69\%) were employed in the 6 months prior to incarceration. Nearly half were Caucasian (49\%); $46 \%$ had never been married, and three-fourths (74\%) had children. Treatment groups were significantly different regarding their racial/ethnic composition; specifically, $53 \%$ of C participants were Caucasian compared to $45 \%$ of E-TES participants (race was a statistical control in outcome analysis).

Early onset for both substance use (mean 14.0 years; SD 5.2) and arrest (mean 17.3 years; SD 6.5) was evident. On average, inmates had 18.2 arrests (SD 20.1), and were most often arrested for drug-related offenses (72\%), property offenses $(76 \%)$, and violent crimes (59\%). The majority of inmates reported lifetime use of cocaine $(71 \%)$ or methamphetamines/amphetamines $(57 \%)$, and $40 \%$ reported opioid use. In the 6 months prior to incarceration, $79 \%$ had used illegal drugs, with $32 \%$ reporting alcohol as the most problematic substance, followed by amphetamines/methamphetamines (21\%), crack/cocaine (18\%), cannabis (13\%), and opioids (8\%). Most (60\%) had received some drug treatment prior to their current incarceration. Treatment groups differed significantly on the substance cited as most problematic during the six months prior to incarceration; $39 \%$ of E-TES participants versus only $25 \%$ of C participants reported alcohol as most problematic; while $\mathrm{C}$ participants were more likely to report opiates $(11 \%)$ and methamphetamines $(24 \%)$ as the most problematic compared to E- 
TES participants ( 5 and $17 \%$, respectively). This variable was included as a statistical control in the outcome analysis.

High HIV/AIDS risk was observed for study subjects. A quarter (25\%) reported lifetime injection drug use and/or an STD (29\%; data not shown), and the average number of sex partners in the 6 months prior to incarceration was 3.9 (SD 7.8). Twothirds $(66 \%)$ engaged in unprotected sex during the same period.

Study participants reported considerable mental health treatment histories and symptomatology. Approximately one-third (36\%) had received mental health treatment ( $23 \%$ received inpatient mental health treatment; data not shown) and/or had been prescribed psychotropic medication (30\%). Nearly two-thirds (59\%) reported serious mental health symptoms, including depression (43\%), anxiety (46\%), and/or hallucinations $(14 \%)$. No significant differences were found between groups on these measures.

\section{Attendance}

\section{Comparison of sessions attended}

Treatment session attendance data were available only for Colorado subjects $(n=325)$, because the Departments of Corrections (DOCs) in KY, PA, and WA were unable to provide attendance data for $\mathrm{C}$ subjects. Table 2 indicates that, in Colorado, participants in both treatment conditions completed an average of 6 sessions (mean $=6.3$ for TES; mean=5.8 for C), or roughly half of the 12 sessions planned. A categorization of the attendance data showed that $17 \%$ of the E-TES group and $14 \%$ of C participants did not attend a single treatment session, meaning that inmates consented to participate in the study, completed the baseline interview and were randomized into a treatment condition, but failed to engage in treatment. Otherwise, reasons for absence typically included a facility transfer, early release, or a subject deciding to end his/her participation (often communicated simply by not attending scheduled treatment sessions). As is evident in Table 2, attendance was quite similar across each of the five levels or categories for both treatment conditions. In summary, no significant

Table 2 Group comparison on sessions attended (Colorado site only)

\begin{tabular}{|c|c|c|c|c|}
\hline Attendance rates & $\begin{array}{l}\text { TES (E) } \\
(n=165) \\
\% / \text { Mean (SD) }\end{array}$ & $\begin{array}{l}\text { Standard Care }(\mathrm{C}) \\
(n=160) \\
\% / \text { Mean }(\mathrm{SD})\end{array}$ & $\begin{array}{l}\text { Total } \\
(n=325) \\
\% / \text { Mean }(\mathrm{SD})\end{array}$ & $\begin{array}{l}\chi^{2}(t \text { test }) \\
p\end{array}$ \\
\hline Mean no. sessions & $6.3(4.4)$ & $5.8(4.3)$ & $6.1(4.4)$ & 0.302 \\
\hline No. of sessions attended & & & & 0.220 \\
\hline No sessions & 17.0 & 14.2 & 15.7 & \\
\hline $1-3$ sessions & 15.2 & 22.5 & 18.8 & \\
\hline 4-7 sessions & 19.4 & 24.4 & 21.8 & \\
\hline $8-11$ sessions & 32.1 & 23.8 & 28.0 & \\
\hline 12 sessions & 16.4 & 15.0 & 15.7 & \\
\hline
\end{tabular}


differences in treatment dose (defined as the number of prescribed sessions attended) were apparent between the $\mathrm{E}$ and $\mathrm{C}$ groups in Colorado prisons.

\section{TES module completion}

Table 3 presents an alternative view of treatment dosage for E-TES only, which illustrates the number of TES modules that participants completed. In this study, TES was planned for $2 \mathrm{~h}$ each week for 12 weeks. The 32 core modules were estimated to require 8 weeks to complete, leaving 4 weeks to explore the 16 optional modules, to repeat core modules, or to select some combination of modules in each category. In fact, modules were completed at a faster pace than anticipated. So, to arrive at a better understanding of treatment dosage, exposure to modules was examined, irrespective of the number of sessions completed.

As shown in Table 3, exposure to TES was relatively high. On average, inmates assigned to E-TES completed 35 modules $(\mathrm{SD}=19)$, including 25 core modules $(\mathrm{SD}=12)$ and 10 optional modules $(\mathrm{SD}=8)$. In addition, nearly three-quarters $(73 \%)$ completed at

Table 3 TES modules completed ( $n=249$ TES participants)

\begin{tabular}{llc}
\hline Modules (maximum) & $\begin{array}{l}\text { Completed any } \\
\%(n)\end{array}$ & $\begin{array}{l}\text { No. completed } \\
\text { M (SD) }\end{array}$ \\
\hline Total modules completed (core and optional) & $86.7(216)$ & $34.84(18.71)$ \\
Core modules completed & $86.7(216)$ & $24.61(12.06)$ \\
$\quad$ Completed 8 modules & $81.5(203)$ & - \\
$\quad$ Completed 16 modules & $77.1(192)$ & - \\
$\quad$ Completed 24 modules & $72.7(181)$ & - \\
$\quad$ Completed 32 modules & $55.8(139)$ & - \\
Optional modules completed & $65.9(164)$ & $10.23(7.50)$ \\
$\quad$ Completed 8 modules & $65.5(163)$ & - \\
$\quad$ Completed 16 modules & $59.0(147)$ & - \\
Core modules detailed & & - \\
Learning to use the program - Training Module (1) & 86.7 & - \\
Relapse Prevention Skills (5) & 86.3 & $4.27(1.73)$ \\
Improving Problem Solving, Decision Making and & 82.7 & $7.21(3.50)$ \\
$\quad$ Self-Management (9) & & \\
Improving Communication and Emotional Self-Regulation Skills $(8)$ & 77.1 & $5.97(3.33)$ \\
Risk Reduction for HIV, AIDS, STIs (9) & 72.7 & $6.29(4.06)$ \\
Optional modules detailed & & \\
Relaxation (3) & 64.7 & $1.94(1.44)$ \\
Time Management (1) & 64.3 & - \\
Anger Management (3) & 65.1 & $1.94(1.44)$ \\
Financial Management (1) & 65.9 & - \\
Communication II (3) & 65.5 & $1.95(1.43)$ \\
Social Recreation (1) & 63.1 & - \\
Risk Reduction (4) & 63.9 & $2.48(1.91)$ \\
\hline
\end{tabular}


least 24 core modules, and more than half (56\%) completed all 32 core modules, with $59 \%$ completing the 16 optional modules. The number of modules contained in each core section varied from 1 (the Training Module in the "Learning to Use the Program" topic) to 9 (in each of 2 topics, "Risk Reduction for HIV, AIDS, and STIs" and "Improving Problem Solving, Decision-Making and Self-Management"). The proportion of TES participants completing each topic ranged from $87 \%$ (Learning to Use the Program) to 73 \% (Risk Reduction for HIV, AIDS, and STIS).

\section{Skills: the Coping Strategies Scale}

The Coping Strategies Scale was used to assess how well inmates applied coping strategies to support abstinence and to detect changes in coping skills from baseline to post-prison follow-up. Items, and the mean scale score, ranged from 1 (never) to 4 (frequently) for specific strategies used in the past 3 months (the baseline interview asked about the 3 months prior to their arrest; the two follow-up interviews asked about the 3 months since being released from prison and for months 4-6 post-prison). In general, inmates in both groups showed statistically significant improvement in coping skills from baseline to 3 months post-prison release, and the improvement was maintained at 6 months post-prison release (i.e., for months $4-6$ since returning to the community). No significant difference in the degree of improvement between the groups was found (Table 4).

\section{Client satisfaction}

Inmates were asked several questions about their satisfaction and overall experience of the substance abuse treatment. Inmates assigned to E-TES rated the treatment experience significantly more favorably on 3 of the 5 scale items. Specifically, compared to control subjects, E-TES subjects reported that their treatment experience was more interesting, yielded more new information, and was more satisfying. Study participants in both groups had low ratings regarding their ability to comprehend the information received in treatment; group differences on these measures were not statistically significant (Table 5).

\section{Discussion}

\section{TES feasibility}

Overall, results from this study demonstrate that it is feasible to implement a computerized substance abuse treatment intervention such as TES in a prison setting. TES was successfully implemented in 10 different prisons operated by four State Department of Corrections systems, each of which presented some challenges regarding installation and implementation. To achieve a successful network in 10 prison computer labs, barriers such as space limitations and compliance with restrictions on inmate access to the internet had to be addressed. In some prisons, space had to be retrofitted, which involved building computer desks and having prison industries install suitable wiring. TES is most conveniently networked using a web browser, but, 


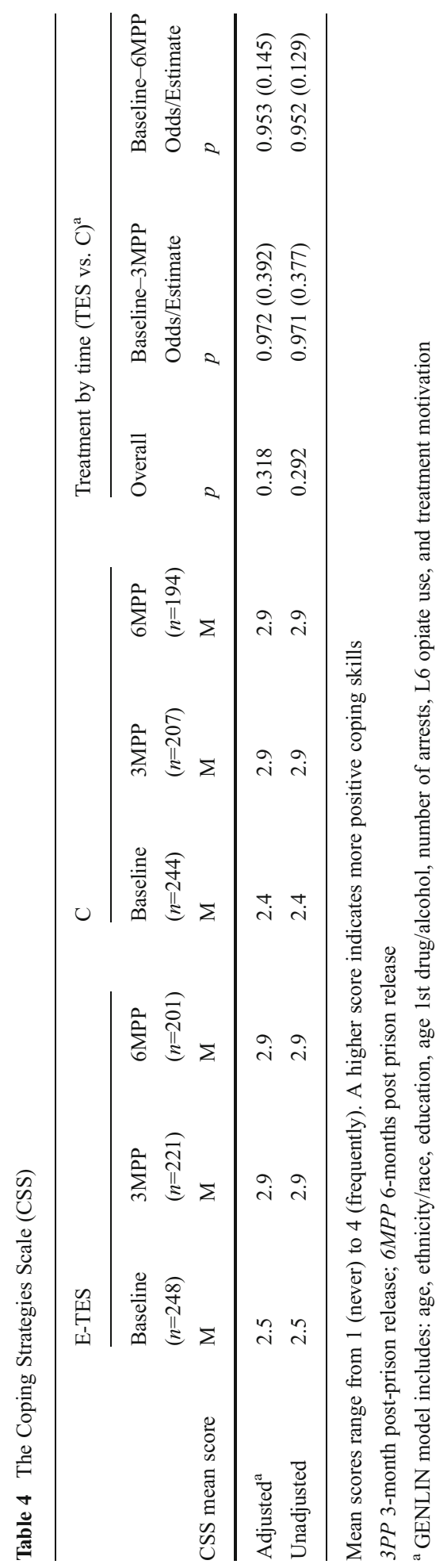


Table 5 Satisfaction and knowledge

\begin{tabular}{|c|c|c|c|}
\hline Question & $\begin{array}{l}\text { E-TES } \\
(n=193) \\
\text { M (SD) }\end{array}$ & $\begin{array}{l}\mathrm{C} \\
(n=183) \\
\mathrm{M}(\mathrm{SD})\end{array}$ & $p$ \\
\hline How interesting was the education you received from your program? & $7.65(2.45)$ & $7.11(2.70)$ & $0.043^{*}$ \\
\hline How useful was the education you received from your program? & $7.83(2.46)$ & $7.39(2.70)$ & 0.095 \\
\hline $\begin{array}{l}\text { How much new information did you learn while participating in } \\
\text { your program? }\end{array}$ & $7.06(2.92)$ & $6.32(3.36)$ & $0.024 *$ \\
\hline $\begin{array}{l}\text { How easy to understand was the information you received from } \\
\text { your program? }\end{array}$ & $3.35(4.00)$ & $3.24(3.80)$ & 0.436 \\
\hline $\begin{array}{l}\text { How satisfied are you with the substance abuse treatment you } \\
\text { received? }\end{array}$ & $8.28(2.48)$ & $7.44(2.88)$ & $0.003 * *$ \\
\hline
\end{tabular}

Scores range from 0 (not) to 10 (very)

$* p<0.05 ; * * p<0.01$

since inmates were not allowed access to the internet, a locally secure set-up was necessary in KY, PA and WA prisons; in these prisons, TES was networked on a standalone server, which provided access only to the intervention and restricted access to all other online content. In Colorado, an online security infrastructure had been established that linked all prison facilities while restricting access to online content, which simplified setting up the TES network. Finally, the project had to ensure that computer equipment met DOC specifications. The investigative team was able to work closely with DOC administrative and IT staff to identify viable solutions to each of these challenges. The result was that 10 computer laboratories, each with 12 individualized workstations, were established.

Once these computer laboratories were established in each prison, additional challenges were encountered in implementing TES. First, because the prison (parole board) required each study participant to complete substance abuse treatment prior to their release, it was necessary to ensure that the experimental intervention (TES) satisfied that treatment mandate for those inmates who agreed to participate in the study. Second, while not required for treatment administered in other settings (e.g., outpatient), prison security protocols required supervision for inmates during TES sessions (TES is intended to be entirely self-directed). Third, although computer laboratories in a few of the prisons were dedicated to TES, prisons in Colorado offered other programming, which competed for laboratory time. In these prisons, research staff had to be particularly flexible around scheduling, and needed to negotiate laboratory time that suited both the project and the facility. Fourth, in many of the prisons, the study expanded inmates' access to treatment, which strained prison staff resources that had been delivering Standard Care. That is, many study subjects received treatment only as a condition of the research study, and some prisons did not have enough counseling staff to accommodate the extra subjects assigned to Standard Care through participation in the study. In these instances, the investigative team supplemented staff resources, hiring counselors to conduct the Standard Care sessions or to assist in delivering Standard Care, thus relieving prison staff of the additional burden. Despite these and other barriers to implementation, TES was made 
available to 258 inmates across 10 prisons during a 6-month period. The results (discussed below) regarding service utilization, skills acquisition, and client satisfaction suggest that TES was feasible to implement, beneficial to participants, and well received.

\section{Service utilization}

Results demonstrated that subjects assigned to the E-TES condition were receptive to the intervention, primarily indicated by the number of TES modules completed. In Colorado, where E-TES and C-Standard Care subjects could be compared on their rates of session attendance, subjects in both groups attended, on average, approximately half (6 of 12) of the prescribed treatment sessions, indicating that TES was at least as attractive and accessible to participants as Standard Care. TES subjects in all 10 prisons completed an average of three-quarters $(24.61$ or $77 \%$ ) of the 32 core TES modules (a range of 18.7$31.0)$ while more than half $(56 \%)$ of TES subjects completed all 32 core modules (a range of $0-96.7 \%$ ). It may be that the low rate of session attendance among TES subjects was influenced, at least in part, because inmates completed the modules at a faster pace than had been anticipated. Taking into account TES module completion, results suggest that ETES subjects received a higher treatment dose than session attendance alone might indicate. That is, C-Standard Care subjects who attended 6 of 12 treatment sessions completed half of the prescribed treatment dose, whereas E-TES subjects who attended the same number of sessions (6 of 12) completed 24 of 32 core TES modules, which is essentially three-quarters of the prescribed treatment dose. Furthermore, using Colorado as an example, where attendance data were available for the control group, more than half (56\%) of all E-TES subjects received a full treatment dose (i.e., completed all 32 core modules), compared to only $15 \%$ of C-Standard Care subjects who received a full dose (i.e., attended all 12 sessions). Those E-TES subjects who went on to explore the 16 additional modules received an additional dose; an average of 10 optional modules were completed, while $58 \%$ completed all 16 optional modules, many of whom re-visited some of the core modules (data not shown in Table 3).

The above finding highlights a distinguishing feature of computerized interventions, which is the flexibility offered with regard to implementation and administration, which can be advantageous in prison settings. In the context of this study, not only could sessions be scheduled at times that were best for inmates to ensure better attendance but more importantly, this self-directed computer intervention allowed subjects to move through the modules at their own pace, facilitating exposure to optional treatment content. C-Standard Care subjects had no opportunity to make-up missed sessions or to accelerate the pace of treatment; missed sessions often meant missed content, while the pace could have met client interest and need or not. Because inmates must reconcile competing demands, and drug treatment rarely emerges as a priority, a flexible computerized intervention like TES has the capacity to deliver needed treatment to a large number of inmates with substance use disorders.

\section{Skills acquisition}

Results demonstrated that subjects assigned to both treatment interventions significantly increased their total and mean scores on the Coping Strategies Scale from baseline to 
follow-up. In addition, the gains that both groups achieved at 3 months were maintained at 6 months. Significant differences were not evident between groups on this measure; in other words, both interventions were equally effective at improving coping skills. TES modules address a number of coping skills that include but are not limited to: managing thoughts and cravings for use (e.g., distracting oneself, delaying the decision to use or not, leaving the situation and seeking support), negative thinking (e.g., thoughtstopping, positive self-talk, substituting positive cognitions for negative cognitions), pleasant activities, decision-making (i.e., thinking ahead to the possible consequences of decisions that are made), problem-solving (i.e., generating multiple solutions and identifying the risks and benefits of each and then choosing a solution), planning for emergencies, drink/drug refusal (e.g., avoiding people who use, saying "no" assertively, changing the topic of conversation), handling criticism, and enhancing positive social support networks. Learning to apply these specific coping skills, whether cognitive or behavioral, is an important component of relapse prevention and for maintaining sobriety. Results from this study suggest that TES imparted healthy and effective coping strategies, thus providing participants with many of the necessary tools to deal with stress and other triggers, potentially helping to prevent relapse to substance use.

\section{Client satisfaction}

Client satisfaction is a critical factor for the successful implementation of any intervention. Compared to subjects who received C-Standard Care, subjects assigned to the TES condition rated their treatment experience more favorably regarding interest, usefulness, and satisfaction. Certainly, it is possible that the positive perception of TES among users contributed to increased participation (i.e., module completion). Findings of a positive client reception to TES are of particular significance in offsetting potential concerns about the willingness to adopt a novel treatment approach, as well as about a treatment approach that involves technology rather than face-to-face contact. Given the challenges of delivering substance abuse treatment in prison, any intervention that inmates view favorably can represent great potential for engagement. Interestingly, subjects in both groups gave their respective interventions low ratings in terms of their ability to comprehend the information presented in treatment, indicating a need to improve both services to be appropriate for the population served so that the most effective treatments can be delivered.

\section{Effectiveness of computerized interventions}

Results from this study are consistent with numerous previous studies that have demonstrated computerized interventions to be as effective as counselor-delivered approaches (Bickel et al. 2011). In fact, computer programs have been used effectively in various therapeutic contexts for over a decade (Murphy and Mitchell 1998; Newman et al. 1997; Selmi et al. 1990). Several recent studies, many of which were controlled clinical trials, have supported the effectiveness of interactive, computerdelivered therapy for the treatment of addictive disorders (see, e.g., Campbell et al. 2013; Carroll et al. 2008; Marsch and Bickel 2004; Marsch et al. 2011; Ondersma et al. 2005, 2007). These studies document typical findings from computer-based treatments where participants report greater program engagement, longer periods of 
abstinence, and greater satisfaction than more standard therapist-based treatments (Bickel et al. 2011). TES was the subject of several of these studies (Campbell et al. 2013; Marsch and Bickel 2004; Marsch et al. 2011), and evidence for its effectiveness is mounting when compared to interventions with similar content delivered by trained therapists, as well as when compared to standard treatment being implemented. In some of these studies, TES has been compared as a standalone treatment, but often it is employed as a "clinician extender," whereby TES modules are used as an adjunct to treatment, freeing face-to-face time for clinicians and increasing the overall capacity for treatment delivery. Ultimately, these studies suggest a variety of ways in which computerized interventions such as TES can be integrated within an existing clinical approach to improve access to quality treatment. These studies do not suggest that computerized interventions should be routinely substituted for counselordelivered therapy.

Because computerized interventions cannot offer the benefits of a strong therapeutic alliance, findings citing their effectiveness, compared to more traditional counselor-delivered therapies, have been met with skepticism. Nonetheless, computerized interventions offer distinct advantages that contribute to their effectiveness. First, computerized interventions can be administered with fidelity to the treatment model, ensuring that all participants receive the same treatment, delivered exactly as intended. In contrast, it is difficult to ensure treatment fidelity when a clinician delivers an intervention, as the delivery will often vary, not only from one clinician to another but also for each clinician from one case to the next. Second, computerized interventions can be administered with much greater flexibility, especially when the intervention is web-based, which allows access from home or on a mobile device, and simplifies scheduling, which should have a positive impact on engagement and compliance. Third, computerized interventions offer privacy and confidentiality that is not possible for those participating in clinician-delivered interventions, particularly in group therapies. This could encourage individuals who have typically resisted more traditional models to participate in treatment, which could subsequently lead to improved outcomes. Finally, computerized interventions increase treatment capacity, which means that more individuals will receive treatment and those who are treated will receive a greater dose.

\section{Study limitations}

A number of limitations affect the interpretation of results presented in this paper. First, although a Certified Addictions Counselor (CAC minimum) administered substance abuse treatment with a psycho-educational format at each site to all offenders in the $\mathrm{C}$ condition over 12 weeks ( $2 \mathrm{~h}$ per week), each of the four DOCs (CO, KY, PA, and WA) delivered their own standard treatment curricula (e.g., SAMHSA 2006). A standardized approach could not be implemented for the $C$ condition, which made it difficult to determine whether a confound to the analysis had been introduced.

Second, inferences regarding service utilization were limited as session attendance data were not available for C-Standard Care subjects in KY, PA, and WA, thereby precluding cross-site comparisons; however, attendance data were available for subjects in Colorado, which supplied 7 of the 10 prisons and nearly two-thirds of 
the study sample. Within Colorado, results showed no significant group differences for session attendance.

Third, some participants did not complete the treatment satisfaction questionnaire, as these items were added to the follow-up protocol during the course of data collection. Nonetheless, data were obtained for $376(87 \%)$ of the 430 participants who completed either a 3- or 6-month follow-up interview. Retrieval bias was not evident for these subjects; instead, completion of items had more to do with when the interview was conducted.

Finally, in developing the paper, generalized linear modeling was used to explore "prison site" as a stratifying measure. As expected, much heterogeneity was observed across prison inmates and settings, but the inclusion of prison site into the models did not affect the findings regarding the effect of treatment condition on the selected outcomes, and was not included in the analyses reported here.

\section{Conclusion}

The initial evidence from this study suggests that: (1) it is feasible to implement TES in prison as the relatively positive findings for service utilization demonstrated; specifically, comparable rates of session attendance between treatment conditions, and high rates of TES module completion for E-TES subjects; (2) TES was equally effective as Standard Care in improving coping strategies; and (3) TES was viewed more favorably than Standard Care on a few measures capturing utility and treatment satisfaction. Collectively, these results show that not only can a computerized intervention like TES be implemented successfully in prison but also that these types of interventions are particularly well suited to correctional settings for inmates with mild to moderate substance use disorders, given the typical barriers to the delivery of substance abuse treatment. If TES is proven to be as effective as Standard Care when compared on longer-term key outcomes, such as substance use, recidivism, and HIV risk behavior, it could present a unique opportunity to expand access to treatment for many substance-using offenders who have traditionally been neglected.

Acknowledgments The authors wish to express their appreciation for the exceptional contributions of their lead research staff; specifically, Doris Weiland from Temple University in Pennsylvania, Tobie Reeser from the University of Kentucky, Meghan Lynch from the University of California Los Angeles and the Washington State DOC site, and Bisma Sayed from the University of Miami. The authors also wish to thank Dr. Barry Brown for his insightful review of the article. Finally, the authors wish to recognize the partnerships established with the three Departments of Corrections (DOC); namely, the Colorado DOC, the Washington State DOC, and the Pennsylvania DOC. Without the assistance of the staff of these systems, the study could not have been conducted. The study was supported by grant \#5RC2-DA-028967, "Computerized Psychosocial Treatment for Offenders with Substance Use Disorders," from the National Institute on Drug Abuse, a division of the National Institutes of Health, as part of the American Recovery \& Reinvestment Act (Recovery Act) of 2009. The content is solely the responsibility of the authors and does not necessarily represent the official views of the NIDA or the National Institutes of Health (NIH).

Conflict of interest In addition to her academic affiliation, Dr. Lisa A. Marsch is affiliated with HealthSim, LLC, the health-promotion software development organization that developed the web-based Therapeutic Education System referenced in this manuscript. Dr. Marsch has worked extensively with her affiliated institutions to manage any potential conflict of interest.

None of the other authors have any conflict of interest relating to the study. 
Open Access This article is distributed under the terms of the Creative Commons Attribution License which permits any use, distribution, and reproduction in any medium, provided the original author(s) and the source are credited.

\section{References}

American Psychiatric Association (APA). (2000). Diagnostic and statistical manual of mental disorders, DSM-IV-TR (4th ed.). Washington, D.C: American Psychiatric Association, Task Force on DSM-IV. Text Revision by the American Psychiatric Association.

Arriola, K. R. J., Kennedy, S. S., Coltharp, J. C., Braithwaite, R. L., Hammett, T. M., \& Tinsley, M. J. (2002). Development and implementation of the cross-site evaluation of the CDC/HRSA corrections demonstration project. AIDS Education and Prevention, 14(Suppl A), 107-118.

Belenko, S., \& Peugh, J. (2005). Estimating drug treatment needs among state prison inmates. Drug and Alcohol Dependence, 77(3), 269-281. doi:10.1016/j.drugalcdep.2004.08.023.

Bickel, W. K., Christensen, D. R., \& Marsch, L. A. (2011). A review of computer-based interventions used in the assessment, treatment and research of drug addiction. Substance Use \& Misuse, 46(1), 4-9. doi:10.3109/10826084.2011.521066. PMCID: PMC3092368.

Bickel, W. K., Marsch, L. A., Buchhalter, A. R., \& Badger, G. J. (2008). Computerized behavior therapy for opioid-dependent outpatients: a randomized controlled trial. Experimental and Clinical Psychopharmacology, 16(2), 132-143. doi:10.1037/1064-1297.16.2.132.

Binder, L. M. (1993). An abbreviated form of the Portland Digit Recognition Test. Clinical Neuropsycholgoist, 7(1), 104-107. doi:10.1080/13854049308401892.

Calsyn, D.A., Hatch-Maillette, M.A., Doyle, S.R., Cousins, S.J., \& Woody, G.E., (2006). Sex under the influence is common for substance abuse treatment patients. Poster presented at the College on Problems of Drug Dependence (CPDD 3 68th Annual Scientific Meeting Program, Scottsdale, Arizona.

Campbell, A.N.C, Nunes, E.V, Matthews, A.G, Stitzer, M., Miele, G.M., Polsky, D., et al. (2013). Internet-delivered treatment for substance abuse: a multi-site randomized controlled clinical trial. Unpublished document.

Carroll, K. M., Ball, S. A., Martino, S., Nich, C., Babuscio, T. A., Nuro, K. F., et al. (2008). Computerassisted delivery of cognitive-behavioral therapy for addiction: a randomized trial of CBT4CBT. American Journal of Psychiatry, 165(7), 881-888. doi:10.1176/appi.ajp.2008.07111835. PMCID: PMC2562873.

Center for Substance Abuse Treatment. (2005). Substance abuse treatment for adults in the criminal justice system. Treatment Improvement Protocol (TIP) Series, No. 44, 337 pgs. U.S. DHHS Publication No. (SMA) 05-4056. Rockville (MD): Substance Abuse and Mental Health Services Administration (SAMHSA). Retrieved February 22, 2013, online at http:/www.ncbi.nlm.nih.gov/books/NBK64137/ pdf/TOC.pdf.

Chandler, R. K., Fletcher, B. W., \& Volkow, N. D. (2009). Treating drug abuse and addiction in the criminal justice system. Journal of the American Medical Association, 301(2), 183-190.

Doane, B. M., Greve, K. W., \& Bianchini, K. J. (2005). Agreement between the abbreviated and standard Portland Digit Recognition Test. Clinical Neuropsychology, 19(1), 99-104. doi:10.1080/ 13854040490524100.

Farabee, D., Prendergast, M., Cartier, J., Wexler, H., Knight, K., \& Anglin, M. D. (2011). Barriers to implementing effective correctional drug treatment programs. The Prison Journal, 79(2), 150-162. http://amityfoundationpress.org/?p=98.

Glaze, L. \& Parks, E. (2012). Correctional populations in the U.S. 2011. NCJ 239972. Bureau of Justice Statistics, Office of Justice Programs, November 2012, 10 pgs. Washington, DC: U.S. Department of Justice. Retrieved February 27, 2013, online at http://bjs.ojp.usdoj.gov/content/pub/pdf/cpus11.pdf.

Hammett, T. (2006). HIV/AIDS and other infectious diseases among correctional inmates: transmission, burden, and an appropriate response. American Journal of Public Health, 96, 974-978.

Kiene, S. M., \& Barta, W. D. (2006). A brief individualized computer-delivered sexual risk reduction intervention increases HIV/AIDS preventive behavior. Journal of Adolescent Health, 39(3), 404-410. doi:10.1016/j.jadohealth.2005.12.029.

Knight, K., Simpson, D.D., \& Hiller, M.L. (1999). Three-year reincarceration outcomes for in-prison therapeutic community treatment in Texas. The Prison Journal, 79(3), 337-51. DOI: 20.1177/ 0032885599079003004. Retrieved February 25, 2013, online at https://www.slu.edu/Documents/ professional_studies/prison_program/Three-Year\%20Reincarceration $\% 20$ Outcomes $\% 20$ for $\% 20$ InPrison\%20Therapeutic\%20Community\%20Treatment\%20in\%20Texas.pdf. 
Litt, M. D., Kadden, R. M., Cooney, N. L., \& Kabela, E. (2003). Coping skills and treatment outcomes in cognitive-behavioral and interactional group therapy for alcoholism. Journal of Consulting and Clinical Psychology, 71, 118-128. doi:10.1037/0022-006X.71.1.118.

Marsch, L. (2012). Leveraging technology to enhance addiction treatment and recovery. Journal of Addictive Diseases, 31(3), 313-320. doi:10.1080/10550887.2012.694606.

Marsch, L. A., \& Bickel, W. K. (2004). Efficacy of computer-based HIV/AIDS education for injection drug users. American Journal of Health Behavior, 28(4), 316-327. doi:10.5993/AJHB.28.4.3.

Marsch, L.A. \& Dallery, J. (2012). Advances in the psychosocial treatment of addiction: The role of technology in the delivery of evidence-based psychosocial treatment. In Danovitch, I. \& Mariani, J. (Eds.) Special Issue of Psychiatric Clinics of North America, 35(2), 481-493. doi:10.1016/ j.psc.2012.03.009.

Marsch, L.A., Bickel, W.K., \& Grabinski, M.J. (2007). Application of interactive, computer technology to adolescent substance abuse prevention and treatment. Adolescent Medicine: State of the Art Reviews (AM:STARS), 18(2), 342-356. Washington, DC: American Academy of Pediatrics.

Marsch, L. A., Grabinski, M. J., Bickel, W. K., Desrosiers, A., Guarino, H., Muehlbach, B., et al. (2011). Computer-assisted HIV prevention for youth with substance use disorders. Substance Use \& Misuse, 46(1), 46-56. doi:10.3109/10826084.2011.521088. PMCID: PMC3091163.

Maruschak, L.M. \& Beaver, R. (2009). HIVin prisons, 2007-08. Bureau of Justice Statistics (BJS) Bulletin, NCJ 228307, December 2009, 12 pgs. Washington, DC: U.S. Department of Justice (DoJ). Retrieved February 22, 2013, online at http://bjs.ojp.usdoj.gov/content/pub/pdf/hivp08.pdf.

Matheson, F. I., Doherty, S., \& Grant, B. A. (2011). Community-based aftercare and return to custody in a national sample of substance-abusing women offenders. American Journal of Public Health, 101(6), 1126. doi:10.2105/AJPH.2010.300094.

Mears, D.P., Winterfield, L., Hunsaker, J., Moore, G.E., \& White, R. (2003). Drug treatment in the criminal justice system: the current state of knowledge. Research Report, January 2003, 104 pgs. Washington, DC: Urban Institute Justice Policy Center. Retrieved February 25, 2013, online at http:// www.urban.org/UploadedPDF/410618 NIDA1_KnowledgeRpt.pdf.

Mitchell, O., Wilson, D. B., \& MacKenzie, D. L. (2007). Does incarceration-based drug treatment reduce recidivism? A meta-analytic synthesis of the research. Journal of Experimental Criminology, 3(4), 353-375. doi:10.1007/s11292-007-9040-2.

Mumola, C., \& Karberg, J. (2006). Drug use and dependence, state and federal prisoners, 2004 (Revised 1/ 19/2007). Bureau of Justice Statistics, Office of Justice Programs, Special Report, NCJ 213530, 11 pgs, October 2006. Washington, DC: U.S. Department of Justice (DoJ). Retrieved February 22, 2013, online at http://bjs.ojp.usdoj.gov/content/pub/pdf/dudsfp04.pdf.

Murphy, L., \& Mitchell, D. L. (1998). When writing helps to heal: email as therapy. British Journal of Guidance and Counseling, 26, 21-32.

National Institute on Drug Abuse (NIDA) (2011). Treating offenders with drug problems: Integrating public health and public safety. Topics in brief, May 2011, 1-2. Public Information and Liaison Branch, Office of Science Policy and Communications, NIDA. Retrieved February 25, 2013, online at http:// www.drugabuse.gov/sites/default/files/drugs_crime.pdf.

Newman, M. G., Consoli, S., \& Taylor, C. B. (1997). Computers in assessment and cognitive behavioral treatments of clinical disorders: anxiety as a case in point. Behavior Therapy, 28(2), 211-235. doi:10.1016/S0005-7894(97)80044-5.

Ondersma, S. J., Svikis, D. S., \& Schuster, C. R. (2007). Computer-based brief intervention: a randomized trial with postpartum women. American Journal of Preventive Medicine, 32(3), 231-238. doi:10.1016/ j.amepre.2006.11.003.

Ondersma, S. J., Chase, S. K., Svikis, D. S., \& Schuster, C. R. (2005). Computer-based brief motivational intervention for perinatal drug use. Journal of Substance Abuse Treatment, 28(4), 305-312. doi:10.1016/j.jsat.2005.02.004.

Postel, M. G., de Haan, H. A., \& De Jong, C. A. (2008). E-therapy for mental health problems: a systematic review. Telemed J E Health, 14(7), 707-714. doi:10.1089/tmj.2007.0111.

Prendergast, M. L., Urada, D., \& Podus, D. (2001). Meta-analysis of HIV risk-reduction interventions within drug abuse treatment programs. Journal of Consulting Clinical Psychology, 69(3), 389-405.

Riper, H., Kramer, J., Smit, F., Conijn, B., Schippers, G., \& Cuijpers, P. (2008). Web-based self-help for problem drinkers: a pragmatic randomized trial. Addiction, 103(2), 218-227. doi:10.1111/j.13600443.2007.02063.x.

Selmi, P. M., Klein, M. H., Greist, J. H., Sorrell, S. P., \& Erdman, H. P. (1990). Computer-administered cognitive-behavioral therapy for depression. American Journal of Psychiatry, 147(1), 51-56. 
Substance Abuse \& Mental Health Services (SAMSHA) (2011). Results from the 2010 National Survey on Drug Use and Health [NSDUH]: Summary of National Findings. NSDUH Series H-41, HHS Publication No. (SMA) 11-4658, 143 pages. Rockville, MD: Substance Abuse and Mental Health Services Administration. Retrieved February 22, 2013, online at http://oas.samhsa.gov/NSDUH/ 2k10NSDUH/2k10Results.pdf.

Substance Abuse and Mental Health Services Administration (SAMHSA) (2006). Counselors manual for relapse prevention with chemically dependent criminal offenders. Technical Assistance Publication (TAP) \#19, Gorski, T.T. \& Kelley, J.M. (eds). DHHS Publication No. (SMA) 06-4217, 135 pgs. Rockville, MD: SAMHSA, Center for Substance Abuse Treatment (CSAT). Retrieved February 25, 2013, online at http://adaiclearinghouse.org/downloads/TAP-19-Counselors-Manual-for-RelapsePrevention-with-Chemically-Dependent-Criminal-Offenders-109.pdf.

Taxman, F.S., Perdoni, M.L., \& Harrison, L.D. (2007). Drug treatment services for adult offenders: The state of the state. Journal of Substance Abuse Treatment, 32(3), 239-254. PMC2266078 doi:10.1016/ j.jsat.2006.12.019. Author manuscript retrieved February 25, 2013, from the NIHMS public access website at http://www.ncbi.nlm.nih.gov/pmc/articles/PMC2266078/.

Zhang, M., Tsiatis, A. A., \& Davidian, M. (2008). Improving efficiency of inferences in randomized clinical trials using auxiliary covariates. Biometrics, 64(3), 707-715. doi:10.1111/j.1541-0420.2007. 00976.x.

This manuscript has not been published elsewhere, nor has it been submitted to any other journal for review.

Michael Chaple, Ph.D., a criminologist, is the Deputy Director of the Center for the Integration of Research \& Practice (CIRP) at National Development \& Research Institutes, Inc. (NDRI) in New York City where he has worked for the past 14 years. Dr. Chaple served as Project Director on numerous NIDAfunded multisite clinical trials, including, most recently, a 3-year multi-site prison study (10 prisons across 4 states) and a 5-year New York State technical assistance initiative. The former evaluated the effectiveness of a computer-based substance abuse treatment intervention for incarcerated offenders, examining its impact on relapse to drug use and HIV drug- and sex-related risk behaviors. The latter, NYSHealth's Center for Excellence in Integrated Care (CEIC), delivered technical assistance to 600 licensed outpatient substance abuse and mental health programs statewide, building staff competencies and program capacity to integrate services for individuals with co-occurring mental health and substance use disorders (COD). An evaluation of the CEIC initiative found significant increases in COD capability among participating programs as well as a strong positive correlation between program capability and client retention in treatment. At present, Dr. Chaple is Co-Director of the Northeast and Caribbean Addiction Technology Transfer Center (NeC-ATTC), funded by SAMHSA and focused on the dissemination of evidence-based practices including (but not limited to) the areas of co-occurring mental health and substance use disorders, HIV testing/prevention, recovery-oriented systems of care, medication assisted treatment and integrated care. Dr. Chaple has primary oversight of all training and technical assistance activities in the territories of New Jersey, New York, Puerto Rico and the U.S. Virgin Islands, delivering 300 training events to 10,000 individuals working in substance abuse, mental health, and primary care with a focus on substance abuse and HIV testing and prevention. As such, Dr. Chaple has more than a decade of experience coordinating and delivery training/ technical assistance that is focused on a variety of evidence-based practices and designed to facilitate practice improvement and improved quality of care.

Stanley Sacks, Ph.D., a clinical psychologist and research scientist, is the Director of the Center for the Integration of Research \& Practice (CIRP), a division of National Development \& Research Institutes (NDRI) in New York City. Dr. Sacks leads an investigative team that, with support from SAMHSA (CSAT and CMHS) and NIH, has conducted rigorous studies establishing the effectiveness of modified TC approaches for co-occurring disorders populations, listed in the National Registry of Evidence-based Programs \& Practices since 2008. Author of numerous publications, Dr. Sacks was the chair and lead writer for TIP 42, Substance Abuse Treatment for Persons with Co-Occurring Disorders, a comprehensive compendium of substance abuse and mental health treatment and research information for persons with cooccurring disorders. He served as the Expert Leader for SAMHSA's COCE (Co-Occurring Center for 
Excellence), a national initiative that provided 40 states with technical assistance in system integration, using learning communities of state stakeholders to facilitate this integration. At present, he is Principal Investigator on several NIDA-funded studies and Director of the New York State Health Foundation's CEIC (Center for Excellence in Integrated Care), charged with delivering technical assistance to promote the integration of substance use and mental health services in an estimated 1,200 outpatient mental health and addiction clinics statewide. Since 2012, Dr. Sacks and his team have led the Northeast and Caribbean Addiction Technology Transfer Center (NeC-ATTC) that serves New Jersey, New York, Puerto Rico, and the U.S. Virgin Islands.

Karen McKendrick, MPH, Data Systems and Analysis Director in the Center for the Integration of Research and Practice (CIRP), has provided statistical and data management services to NDRI for over 15 years, and has made significant contributions to all of the research CIRP has undertaken. She has developed extensive detailed data management protocols that govern all CIRP studies. With broad ranging skills in data analytic activities, Ms. McKendrick has training and expertise in specialized analytic methods such as hierarchical linear modeling, meta-analysis, structural equation modeling, propensity analysis, etc. as well as in standard methodologies such as ANOVA and R-MANOVA. She has authored and co-authored several papers relating to the treatment of substance use and co-occurring disorders.

Lisa A. Marsch, Ph.D. is the Director of the Center for Technology and Behavioral Health at Dartmouth College (www.c4tbh.org) and a faculty member of the Department of Psychiatry at Dartmouth College. The Center for Technology and Behavioral Health is a P30 "Center of Excellence" supported by the National Institute on Drug Abuse (NIDA), composed of an interdisciplinary research and development group focused on the systematic application of cutting-edge technologies to the delivery of behavior change interventions targeting substance use disorders and behavioral health. With funding from NIH, Dr. Marsch has led a line of research focused on the development and evaluation of state of the art, technology-based (mobile-, and Internet-delivered) interventions targeting substance abuse and mental health. These technology-based therapeutic tools reflect an integration of science-based behavioral interventions with evidence-based informational technologies. This work has been conducted in a variety of settings, including physician offices, substance abuse treatment programs, educational settings and via the Internet. This research has provided novel empirical information regarding the role that technology may play in improving the prevention and treatment of behavioral health issues in a manner that is costeffective, ensures fidelity and enables the rapid diffusion and widespread adoption of science-based interventions.

Steven Belenko, Ph.D. is Professor in the Temple University Department of Criminal Justice. He is also adjunct Professor at the Department of Psychiatry at the University of Pennsylvania School of Medicine, and is Director of the Methods Core for the Center for Behavioral Health Services and Criminal Justice Research at Rutgers University. Dr. Belenko's research interests focus on strategies for improving the implementation of evidence-based drug treatment and other health services into the criminal justice and juvenile justice systems, the impact of substance abuse and other health problems on the adult and juvenile justice systems, and HIV service needs and interventions for adult and juvenile offenders.

Carl Leukefeld, DSW is Professor and Chair of the Department of Behavioral Science and founding Director of the Center on Drug and Alcohol Research at the University of Kentucky. He is also the Bell Alcohol and Addictions Endowed Chair. He came to the University of Kentucky in 1990 to establish the Center on Drug and Alcohol Research from the National Institute on Drug Abuse (NIDA) where he filled administrative and research positions. He was also the Chief Health Services Officer of the United States Public Health Service. Dr. Leukefeld has published over 200 articles, chapters, books and monographs. He has taught the undergraduate Alcohol and Problem Drinking Course, the Dependency Behavior graduate course, and the Introduction to Clinical Medicine course for medical students. He currently is a reviewer and consulting editor for five journals, grant reviewer, and has been a member of the NIH CommunityLevel Health Promotion Study Section and the NIH/NIDA Health Services Initial Review Group. His research interests include treatment interventions, HIV prevention, criminal justice sanctions, and health services. 
Michael Prendergast, Ph.D. is the Director of the Criminal Justice Research Group at the UCLA Integrated Substance Abuse Programs. He has been Principal Investigator of numerous state and federally funded projects to study drug treatment strategies in the criminal justice system. He has also conducted four meta-analyses on the effectiveness of drug abuse treatment. His research interests include treatment interventions for drug-abusing offenders, systematic reviews of treatment effectiveness, and strategies for implementing evidence-based practices.

Michael French, Ph.D. (www.mtfrench.com) is a health economist and professor in the Department of Sociology at the University of Miami, with secondary appointments in the Department of Economics and Department of Epidemiology and Public Health. He is also director of the Health Economics Research Group (www.miami.edu/herg) in the Department of Sociology and research director of the Health Administration and Policy Program in the School of Business Administration. His research interests and experience includes health policy and program evaluation, substance abuse research, pharmaco-economics, alternative health care delivery systems, human resource economics, and the economics of crime. He has been principal investigator or project leader on numerous research grants with the National Institutes of Health, the Robert Wood Johnson Foundation, and several state agencies. Dr. French served on the Health Services Research Initial Review Groups (IRG) for NIDA (1995-2004) and NIAAA (1998-2001), as well as various Extramural Contract and Grant Review Committees for public and private organizations. He is currently on the editorial board for Health Services Research, Evaluation and Program Planning, Journal of Mental Health Policy and Economics, and Journal of Substance Abuse Treatment and serves on several research advisory boards for universities and private organizations. He was a technical consultant for the National Science Foundation and a technical advisor on evaluation studies of health care programs for the Robert Wood Johnson Foundation. In addition, he has provided expert testimony on several legal cases, serves as a research consultant to various public and private organizations, and is a frequent referee for numerous peer-reviewed professional journals. Dr. French has published over 150 peer-reviewed articles in a variety of multidisciplinary professional journals including Journal of Health Economics, American Journal of Public Health, Medical Care, Medical Care Research and Review, Criminology, American Journal of Health Promotion, Health Services Research, Labour Economics, Social Science and Medicine, Journal of Substance Abuse Treatment, Evaluation and Program Planning, Health Economics, Journal of Quantitative Criminology, Journal of Adolescent Health, The Gerontologist, Journal of the American Board of Family Medicine, Journal of Studies on Alcohol, Law and Policy, Journal of Public Health Policy, Social Science Research, Drug and Alcohol Dependence, Applied Economics, Journal of Health and Social Behavior, Justice Quarterly, Public Health Reports, Evaluation and the Health Professions, Telemedicine and e-Health, Economics of Education Review, Journal of Internal Medicine, Addiction, Social Science Quarterly, Social Science Research, Journal of Mental Health Policy and Economics, Journal of Behavioral Health Services and Research, Evaluation Review, Population Health Management, and Southern Economic Journal. 